\title{
Effect of Moisture Sorption Behavior on Color Quality of Cassia Alata Leaves
}

\author{
Norawanis Abdul Razak ${ }^{1, *}$, Abdul Razak Shaari ${ }^{1}$, Nur Ain Mohd Shariff ${ }^{1}$, and Lee Yit Leng ${ }^{1}$ \\ ${ }^{1}$ Faculty of Engineering Technology, Universiti Malaysia Perlis (UniMAP), Campus of UniCITI \\ Alam Sungai Chuchuh, Padang Besar, 02100 Perlis, Malaysia.
}

\begin{abstract}
The Cassia alata leaf is widely used for the medical uses as it is beneficial for treatment of skin diseases such as purities, eczema and allergy. The moisture sorption behavior included desorption and adsorption of $C$. alata leaves were investigated using standard static gravimetric method. The sorption isotherm was obtained at ambient temperature $24{ }^{\circ} \mathrm{C}$ and with the equilibrium relative humidity (ERH) range from 11.3 to 84.3 $\%$. The equilibrium moisture content (EMC) of C. alata increased from 8.67 to $28.50 \mathrm{~g}$ water/dry matter with increasing ERH during desorption. It is similar to adsorption which the EMC increased from 21.28 to $32.85 \mathrm{~g}$ water/dry matter. The color quality of $C$. alata leaves were lower with increasing the ERH.
\end{abstract}

\section{Introduction}

An increase population's awareness about the negative effect on consuming synthetic medicine urge the community to find the alternative treatment using natural herb product. In order to perform good quality of herb, it is crucial to get appropriate moisture content of the herb during the drying process. High moisture content of the herbs would limit their shelf life and complicates their transport and storage [1]. Therefore, to reduce the moisture content, it is necessary to submit these herbs to a dehydration process. the moisture sorption isotherm are divided into two (adsorption) by addition of water to dry sample and (desorption) by removing the water from wet sample [2]. The study of moisture sorption is important to preserve the function of bioactive compounds constituent and maintain longer lifespan consumer.

In addition to moisture content, the color of the dehydrated herbs is another important quality factor, which is affected by the operation conditions. Food color usually is the first quality parameter evaluated by consumers and is critical in the acceptance of the products. In addition, color measurement is an objective parameter for the evaluation of quality changes during herb processing, and storage [3].

Cassia alata herb is traditionally used to treat a number of diseases such as constipation, skin problems, stomach pain, respiratory and digestive ailments [4]. The moisture content controlling has great influence on the quality of dehydrated $C$. alata. The removal of

* Corresponding author: norawanis@unimap.edu.my 
moisture prevents the growth of microorganisms which deteriorate quality of herbs while while too low moisture content can badly influence the color, texture and even destroy nutrition contents of herbs. The colour measurement of food is commonly used in an alternate way to determine the quality variations as they are faster than a complete physicochemical examination. However, there is lack of information on the effects of moisture sorption behavior on the color changes of $C$. alata leaves. Thus, the aims of this study were to determine the moisture sorption isotherms and color changes of $C$. alata leaves at the various relative humidity range from 11.30 until $84.34 \%$. The hypothesis of this study is that the color quality of $C$. alata leaves decrease with the increasing equilibrium moisture content. Therefore, it has been expected to determine a suitable moisture content range of the leaves for preserving the color quality of $C$. alata during industrial scale production and storage.

\section{Materials and methods}

This section provided the preparation of material used and the methods that were utilized to analyze the samples.

\subsection{Preparation of materials}

The fresh Cassia alata leaves were collected randomly from Institute of Sustainable Agrotechnology (INSAT), which located at Sungai Chuchuh, Perlis. The samples were dried immediately using oven for 24 hours at $40{ }^{\circ} \mathrm{C}$.

\subsection{Development of moisture sorption isotherm}

The static gravimetric method with different saturated salt solution (ranged from 11.30 until $84.34 \%$ ) was used to determine the equilibrium moisture content (EMC) of the samples. The saturated salt solutions were placed in the desiccators to give different range of relative humidity exposed to the herbs. The desiccators were placed at room temperature $\left(24{ }^{\circ} \mathrm{C} \pm\right.$ $0.1^{\circ} \mathrm{C}$ ). About 2.0 to 2.5 gram of the fresh and dried samples for desorption and adsorption experiments, respectively, were prepared triplicate in each desiccator. The weight of the sample was recorded every 2 days by using analytical balance. The equilibrium of moisture content was considered to have reached when the weight difference for three consecutive weights was less than $1 \mathrm{mg}$.

Table 1. Saturated salt solutions used to establish the equilibrium moisture content (ERH) at different levels from 11.30 to $84.34 \%$ (modified from Greenspan, 1977)

\begin{tabular}{|c|c|}
\hline Saturated Salt Solutions & Relative Humidity at ambient temperature $\left(\mathbf{2 4}{ }^{\circ} \mathbf{C}\right)$ \\
\hline Lithium chloride & 11.30 \\
\hline Magnesium chloride & 33.78 \\
\hline Sodium bromide & 57.57 \\
\hline Sodium chloride & 75.29 \\
\hline Potassium chloride & 84.34 \\
\hline
\end{tabular}




\subsection{Determination of equilibrium moisture content}

The equilibrium moisture content was measured using Equation 1.

$$
\text { EMC d. b }=\frac{\text { weight }_{\text {eq }}-\text { weight }_{d m}}{\text { weight }_{d m}}
$$

Where,

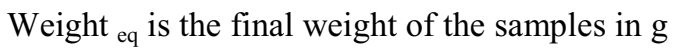

Weight $\mathrm{dm}$ is the dry matter weight of the samples in $\mathrm{g}$.

\subsection{Determination of color quality}

The determination of the color quality was based on lightness $\left(\mathrm{L}^{*}\right)$, greenish to reddish $\left(a^{*}\right)$, and blue to yellowish $\left(b^{*}\right)$ color. The color quality of the sample were determined using colorimeter. The readings were recorded in triplicate.

\section{Results and discussion}

In this section, the pattern of the moisture sorption isotherms and the color changes of the materials were discussed in detail.

\subsection{Moisture sorption isotherms of cassia alata leaves}

The moisture sorption isotherms of the Cassia alata leaves were determined at ambient temperature $\left(24{ }^{\circ} \mathrm{C}\right)$ and different relative humidity range from 11.30 to $84.34 \%$. Desorption and adsorption equilibrium moisture content (EMC) were shown in Table 2. In desorption experiment, the fresh $C$. alata leaves held lowest water content $(8.67 \mathrm{~g}$ water/dry matter) at the lowest equilibrium relative humidity (ERH) $(11.30 \%)$. Whereas, the C. alata leaves obtained highest EMC (28.50 g water/dry matter) at the highest ERH $(84.34 \%)$. This finding was similar with work of Bejar et. al. [5], which also found that the dried leaves hold a large amount of water at high relative humidity.

For the adsorption, the EMC increase from 21.28 to $32.85 \mathrm{~g}$ water/dry matter as the ERH increased. This could be attributed to the adsorption water into the leaves as increasing ERH. The water moved from the high concentration of water to the lower concentration of water thus increasing in weight for adsorption slowly. This finding agreed with work of Abdul Razak et. al. [6], who also found the dried leaves with lower moisture content results in increment of moisture content after prolong storage.

\subsection{Effect of equilibrium relative humidity (ERH) on the color quality of cassia alata leaves}

The determination of the color quality is based on lightness $\left(\mathrm{L}^{*}\right)$, greenish to reddish $\left(a^{*}\right)$, and blue to yellowish $\left(b^{*}\right)$ color. For $\mathrm{L}^{*}$, the scale is given as 0 which is black and 100 as white. For $\mathrm{a}^{*}$, negative value indicates greenness and positive value indicates reddish. Meanwhile for $b^{*}$, negative value means blue and positive indicates that the yellowish. The effect of equilibrium relative humidity $(\mathrm{ERH})$ on the color quality of $C$. alata leaves in desorption experiment is as shown in Table 3 . The results showed that the $\mathrm{L}^{*}$ values of the 
leaves decreased as the ERH increased. The highest of $\mathrm{L}^{*}$ was 54.09 at the lowest relative humidity (RH) while the lowest was 44.65 at $84.34 \% \mathrm{RH}$.

Table 2. EMC values for desorption and adsorption of Cassia alata leaves at different ERH.

\begin{tabular}{|c|c|c|c|}
\hline \multicolumn{2}{|c|}{ Desorption } & \multicolumn{2}{c|}{ Adsorption } \\
\hline ERH (\%) & EMC (d.b) & ERH (\%) & EMC (d.b) \\
\hline 11.30 & $8.67 \pm 0.28$ & 11.30 & $21.28 \pm 1.20$ \\
\hline 32.78 & $11.03 \pm 0.36$ & 32.78 & $22.26 \pm 1.51$ \\
\hline 57.57 & $16.05 \pm 0.81$ & 57.57 & $26.57 \pm 0.17$ \\
\hline 75.29 & $24.45 \pm 0.45$ & 75.29 & $30.12 \pm 1.13$ \\
\hline 84.34 & $28.50 \pm 0.19$ & 84.34 & $32.85 \pm 0.51$ \\
\hline
\end{tabular}

*Mean \pm standard deviation. The samples were prepared in triplicate.

Table 3 shows an increase in a* values of the leaves with increasing the RH $(-6.44$, $6.29,-5.55,-2.25,2.50$ respectively). The green colors of leaves decreased as they were undergone desorption process. The change of color was probably due to degradation of chlorophyll. The $\mathrm{a}^{*}$ value was also observed decreasing from green to reddish as the degradation of the chloropyll occurred [7]. The chloropyll was a main pigment of the leaves in order to retain the green color of the $C$. alata leaves with the humidity treatment. Besides that, Table 3 also showed the results of $b^{*}$ of $C$. alata at different relative humidity. The $b^{*}$ value decreased from 20.49 to 16.34 with increasing relative humidity.

Table 3. Effect of different relative humidity conditions for the color quality in Cassia alata leaves for desorption

\begin{tabular}{|c|c|c|c|}
\hline Relative Humidity (\%) & $\mathbf{L}^{*}$ & $\mathbf{a}^{*}$ & $\mathbf{b}^{*}$ \\
\hline 11.30 & $54.09 \pm 0.71$ & $-6.44 \pm 0.39$ & $20.49 \pm 0.38$ \\
\hline 32.78 & $53.16 \pm 2.98$ & $-6.29 \pm 0.08$ & $21.13 \pm 1.48$ \\
\hline 57.57 & $51.39 \pm 4.63$ & $-5.55 \pm 0.60$ & $20.87 \pm 0.42$ \\
\hline 75.29 & $48.91 \pm 2.40$ & $-2.25 \pm 1.22$ & $18.84 \pm 1.30$ \\
\hline 84.34 & $44.64 \pm 2.56$ & $2.50 \pm 1.25$ & $16.34 \pm 3.53$ \\
\hline
\end{tabular}

$*$ Mean \pm standard deviation. The samples were prepared in triplicate.

Table 4 shows the effect of equilibrium relative humidity (ERH) on the color quality of C. alata leaves in adsorption experiment. The highest $\mathrm{L}^{*}$ value $(52.56)$ was observed at $57.57 \% \mathrm{RH}$ while the lowest was 35.83 at $75.29 \% \mathrm{RH}$. This finding was similar with work of Abdul Razak et. al. [6], which also found that the $\mathrm{L}^{*}$ value of dried leaves decreased from 46.65 to 44.68 after 10 to 30 days storage. Nevertheless, an increase in a* values of the leaves was observed with increasing the relative humidity. The highest $\mathrm{a}^{*}$ value was 4.01 at $84.34 \% \mathrm{RH}$ while the lowest $(-5.50)$ at $32.78 \% \mathrm{RH}$. The parameter of a* was important as it indicates the greenness of leaves and subsequently the quality of leaves. According to Rudra et. al. [8], the degree of greenness is an important characteristic for customers to determine the final dried products. 
Table 4: Effect of different relative humidity conditions for color quality on Cassia alata leaves for adsorption

\begin{tabular}{|c|c|c|c|}
\hline Relative Humidity (\%) & $\mathbf{L}^{*}$ & $\mathbf{a}^{*}$ & $\mathbf{b}^{*}$ \\
\hline 11.30 & $36.45 \pm 2.75$ & $-3.18 \pm 0.19$ & $13.75 \pm 0.72$ \\
\hline 32.78 & $51.00 \pm 3.34$ & $-5.50 \pm 0.55$ & $25.64 \pm 4.53$ \\
\hline 57.57 & $52.26 \pm 1.74$ & $-4.00 \pm 0.59$ & $25.21 \pm 3.24$ \\
\hline 75.29 & $35.83 \pm 1.22$ & $0.19 \pm 0.39$ & $19.90 \pm 3.28$ \\
\hline 84.34 & $46.01 \pm 4.31$ & $4.01 \pm 0.20$ & $18.85 \pm 5.53$ \\
\hline
\end{tabular}

* Mean \pm standard deviation. The samples were prepared in triplicate.

During the adsorption process, the leaves turned out brown color. This probably due to entering and removing of the water on the leaves itself. The color changes of $C$. alata could be attributed to the conversion of chlorophyll to pheophytins at high relative humidity and subsequently the leaves quality was affected in the presence of excessive water [7]. It appears that the $\mathrm{b}^{*}$ value of $C$. alata was highest at $32.78 \% \mathrm{RH}$ and declining with increasing relative humidity However, the lowest $b^{*}$ value (13.75) was found at 11.30 $\%$ RH. This suggests that the carotenoid compound in $C$. alata can be sustained even at $32.78 \%$ RH.

\section{Summary}

The study of moisture sorption isotherm is important to preserve the function of bioactive compounds constituent and maintain longer lifespan consumer. With higher relative humidity, the equilibrium moisture content of Cassia alata increased for both adsorption and desorption process. However, the color quality of $C$. alata leaves was lower with increasing relative humidity. This study suggests that the color quality of $C$. alata was the best at the relative humidity of 32.78 . Low relative humidity was better in preserve the color quality of $C$. alata leaves.

This study was financially supported by the Ministry of Higher Education Malaysia (Fundamental Research Grant Scheme (FRGS9003-00520); the research facilities of the Institute of Sustainable Agrotechnology (INSAT) and Faculty of Engineering Technology, UniMAP.

\section{References}

1 P.B. Silva, C.R. Duarte, M.A.S. Barrozo, 8, 62 (2015)

2 Z. Yan, M.J. Sousa-Gallagher, F.A.R. Oliveira, J. Food Eng., 86 , 342 (2008)

3 F. Pedreschi, J. Len, D. Mery, P. Moyano, Food Res. Int., 39, 109 (2006)

4 M.A. Adiana, M.P. Mazura, J. Mol. Struct, 991, 84 (2011)

5 A.K. Bejar, N.B. Mihoubi, N. Kechaou, Food Chemistry, 132, 1728 (2012)

6 N. Abdul Razak, A.R. Shaari, A.F. Simbas, S. Abdullah, 5 (2014)

7 S. Gonda, L. Toth, G. Gyemant, M. Braun, T. Emri, G. Vasas, Phytochem. Anal., 23, 88 (2012)

8 S.G. Rudra, H. Singh, S. Basu, U.S. Shivhare, J. Food Eng., 86, 379 (2008) 